\title{
Context and consensus
}

\author{
Alan Gilchrist \\ Cura Consortium and TFPL Ltd. (Reino Unido)
}

\section{Resumen}

La ciencia de la información, como la de la gestión, está sometida a continuas olas de pensamiento. La última que ha llegado al campo de la información es el fenómeno Web 2, una colección de herramientas de interconexión que incluyen blogs, wikis y RSS. Esta ponencia presenta algunas perspectivas de carácter tentativo sobre el posible impacto de la Empresa 2.0 — como se ha denominado la Web 2 en el sector empresarial- y sobre los problemas que pueden plantearse para desarrollarla con éxito, así como sobre su relación con aspectos más tradicionales de la gestión de la información.

Palabras clave: Computación social. Web 2. Ciencia de la información.

\section{Abstract}

Information science, as with management science, is subject to new waves of thinking. The latest to arrive on the information scene is the Web 2.0 phenomenon, which can be viewed as a collection of social networking tools including blogs, Wikis and RSS, though as a movement it is much more complex. This paper presents some tentative views on the likely impact of Enterprise 2.0 on the corporate sector (as Web 2.0 has been called in this arena); and of possible problems in realising successful outcomes, and of relating them to more traditional aspects of information management.

Keywords: Social computing. Social networking. Web 2.0. Information Science.

\section{Introduction}

It is usually regarded as bad practice to give opaque titles to papers, especially if they may be published. In this case, the title came to this author before the content, and seemed to encapsulate the possible conflict between structured enterprise-wide information systems seeking to meet organizational objectives, and the new wave of the "democratisation" of information offered by Web 2.0; and beginning to be adopted by, and within, enterprises under the name Enterprise 2.0. Writing the paper has not been easy as there is very little firm evidence of the take-up of these 
technologies by enterprises, let alone any clear evaluation of the outcomes. On the other hand, there is a flood of comment and opinion on what it all means and what it can offer, with new items arriving every day in print and through discussion lists, not to mention the blogs and Wikis which this paper describes. This paper, then, presents a brief review of Web 2.0 and Enterprise 2.0 at the time of writing, together with tentative views of the phenomenon.

\section{Web 2.0}

The origin of the expression Web 2.0 has been claimed by Tim O'Reilly, the CEO of O'Reilly Media, as coming out of a conference brainstorming session between himself and MediaLive International. This produced an article in which O'Reilly (2005) tried to clarify just what was meant by the expression Web 2.0. Though much of what he said concerned commercial aspects of less interest to this paper, there were some interesting pointers to what was happening on the Internet. O'Reilly enunciated seven principles:

\section{The Web as platform}

Here, he showed how the scene had changed from the Netscape era to that now dominated by Google. Whereas Netscape had "framed the 'web as platform' in terms of the old software paradigm, their flagship product (being) the web browser, a desktop application", Google "began its life as a native web application, never sold or packaged, but delivered as a service". In other words, he said, "Google happens in the space between browser and search engine and destination content server, as an enabler or middleman between the user and his or her online experience".

\section{Harnessing collective intelligence}

Here O'Reilly cites Yahoo! and Amazon as pioneers in the move towards bringing the users into a shared space. This is a principal focus of this paper as it is possibly the main argument put forward by users in support of Web 2.0.

\section{Data is the next Intel inside}

This principle is concerned with the big question of who owns the data, and what they choose to do with it. This will continue to be, for some time to come, a commercial battlefield.

\section{End of the software release cycle}

It follows from the first principle above that, as software will be delivered as a service rather than as a product, it must be maintained on a daily basis, which puts an enormous pressure on the service provider. O'Reilly also claims that this new paradigm leads to the need to treat users as co-developers, where some sites are in an almost "perpetual beta" condition. 


\section{Lightweight programming modules}

The previous principle suggests that programming models should allow for loosely coupled systems, allowing syndication rather than mere coordination.

Software above the level of a single device

Again following on from the software principles above, the need is perceived for Web 2.0 software to be capable of running on any device, particularly in the fast emerging era of mobile computing.

\section{Rich user experiences}

And last, but by no means least, perhaps a hope rather than a principle, the golden prize of user satisfaction.

These are all interesting observations, albeit expressed with all the enthusiasm of an American entrepreneur. But not everybody is so impressed. Jack Schofield (2005), the IT Correspondent for the British daily newspaper, The Guardian is one such person, and quotes another American, Joel Spolsky, CEO of Fog Creek Software as saying "The term Web 2.0 particularly bugs me. It's not a real concept. It has no meaning. It's a big, vague, nebulous cloud of pure architectural nothingness".

As we shall see later in this paper, Web 2.0 should rather be seen in terms of natural evolution than as a fully designed system.

\section{Components of Web 2}

From the user perspective the major components of Web 2.0 are those incorporating social interaction, including blogs, Wikis, bookmarking and tagging, using folksonomies, RSS (enabling Mash-ups) and a growing range of actual web-based facilities.

\subsection{Blogs}

A simple definition of a blog is "A web log: an online diary or frequently updated personal web page" (BlogsCanada, n. d.). One journalist (Longbottom, 2006) has claimed that 75,000 new blogs are being created every day, while Christopher Barger, the IBM Blogger-in-Chief has said in an interview that "the number of blogs - not the number of active or good ones - doubles every five months, and where there were less than 2 million in 2003, there are now more than 32 million (as at mid-2006)" (Buckley, 2006). Barger goes on to suggest that "One per cent of them might be worth the screen that they're written on". Two common failings are that they are infrequently updated and that the entries are chronological, rendering them difficult to use retrospectively.

Scire. $14: 2$ (jul.-dic. 2008) 13-29. ISSN 1135-3716. 
Where blogs started as being almost entirely personal, five types have now evolved (Gotta, 2004): $a$ ) internal blogs (targeted to employees only); $b$ ) external blogs (focused on the general public); c) thematic blogs (linked to a particular event or project); $d$ ) sponsored blogs (posted by an employee, authorised but not necessarily endorsed by, the company; $e$ ) personal blogs. It is clear from this list that organizations are beginning to adopt this technology.

\subsection{Wikis}

The word Wiki is taken from the Wiki Wiki bus service at Honolulu Airport, and means double quick. In Web terms "it is a type of website that allows users to add, remove, or otherwise edit all content, very quickly and easily, sometimes without the need for registration" (Wikipedia contributors, 2006).

Perhaps the most famous Wiki is the Wikipedia, and its short history is illuminating in the debate on Web 2.0 artefacts. The Wikipedia allows, with some screening, anybody to contribute and/or edit entries in its online encyclopaedia. As has been widely reported, (for example Orlowski, 2006; Wikipedia contributors, $2006 \mathrm{~b}$, the latter reference from the Wikipedia itself), the renowned scientific journal Nature reported that of the 41 science articles it reviewed, there were 162 mistakes in Wikipedia versus 123 for Britannica. The details of this survey have been hotly disputed by Britannica, which is conscious of its vulnerability in the age of electronic media, but Nature has refused to retract its findings. However, some of the criticisms of Wikipedia have been sufficiently telling for Larry Sanger, one of the co-founders of Wikipedia to announce that he has plans for a new online service "a Wikipedia written by experts" (Moody, 2006).

A problem with corporate Wikis, noted by one journalist (Hogge, 2006) is that meetings she has attended have finished with the words "OK, let's continue this discussion on the Wiki", only to discover months later that nobody has. This journalist suggests that Wikis "need a critical mass of people who regularly edit them in order to produce a functional document".

\subsection{Folksonomies}

The term folksonomies was coined by information architect Thomas Vander Wal. The Wikipedia definition (Wikipedia contributors, 2006c) is "an Internetbased information retrieval methodology consisting of collaboratively generated, open-ended labels that categorize content such as Web pages, online photographs, and Web links". This is possibly the most contentious aspect of Web 2.0 techniques, as it appears to run counter to the fundamental beliefs of librarians and information scientists, while having an enormous appeal to the far wider public.

Vander Wal has said on a members-only discussion list (IAI members discussion list, n. d.) that folksonomies have three elements that must be as clear 
as possible: a) the object being tagged - and Vander Wal notes that much blog tagging fails because it is never clear if it is the blog post being tagged, the objects being written about, or something in between; $b$ ) the tag itself; $c$ ) an identity. He adds that folksonomy must also be done through free tagging and not from controlled vocabularies.

Studies are beginning to be undertaken of tagging, for example one by researchers at the Hewlett Packard Laboratories (Golder \& Huberman, 2005). The authors conclude that "The prevalence of tagging with a very large number of tags and according to information intrinsic to the tagger demonstrates that a significant amount of tagging, if not all, is done for personal use rather than public benefit".

\subsection{Miscellaneous technologies and facilities}

A few other Web 2.0 technologies and facilities are worth a brief mention:

- RSS, variously spelt out as Really Simple Syndication, Rich Site Summary, and RDF Site Summary, is "a family of web feed formats, specified in XML and used for web syndication" (Wikipedia contributors, 2006de). Aggregators are then used to allow a website's frequent readers to track updates on the site.

- RSS allows for another device called mashups "a website or web application that uses content from more than one source to create a completely new service" (Wikipedia contributors, 2006f). Google has fed into this growth area with its Googlemaps, used for example by the police force in Chicago to put a map of the city on the Web showing at street level where crimes have been committed.

- Podcasting is "the method of distributing multimedia files, such as audio or video programmes over the Internet using syndication feeds" (Wikipedia contributors, $2006 \mathrm{~g})$.

- Ajax (shorthand for Asynchronous JavaScript and XML) is "a web development technique for creating interactive web applications" (Kyrin, n. d.).

Bradley (2006) has written about families of new Web 2.0 facilities including online calendars (updated by RSS feeds), personalized search engines (with personal profiles of interests and websites) and collaborative word processors.

\section{Social computing}

Harnessing collective intelligence was one of the Web 2.0 principles put forward by O'Reilly (2005), and there is no doubt that behind all the hype and the commercial interest, Web 2.0 is a "people thing", touted by many as being the "democratisation" of information. Whatever that might mean, the emphasis is on the word "social", and it is found in many phrases, often used interchangeably, though having slightly different meanings. Social computing, for example, has been defined quite widely as "The interplay between persons, their social behaviours and interactions with computing technologies" (Social networking,

Scire. 14 : 2 (jul.-dic. 2008) 13-29. ISSN 1135-3716. 
2006), while the more specific Social networking is "The activity of meeting friends or business contacts through networking services offering blogs, chat, e-mail, instant message and videoconference. The scope includes Web sites that host private or open virtual communities" (Social networking, 2006). Covering tagging and folksonomies, Social bookmarking is defined as "a web based service, where shared lists of user-created Internet bookmarks are displayed" (Wikipedia contributors, 2006h).

Gotta (2004) maintains that "Interest in social computing is being driven by the continued extension and virtualization of work, workforces, work associations, and the workplace itself, as well as the blurring of boundaries between work and lifestyle needs". There is an interesting aspect of this, as pointed out by Schofield (2006) when he says that "There is a new generation entering the workforce who were all born after the IBM PC. Most of them have grown up with home computers and games consoles. Most likely they are also familiar with camera phones, IP telephony, instant messaging, blogging, podcasting and using webcams for simple videoconferencing". The effect of this on the enterprise may be significant. Till now, he says "Businesses have tended not to exploit multimedia because the equipment was too expensive and it required too much staff training. Now they have the equipment and they are hiring staff who may already have the skills". This newly found know-how also brings intense dissatisfaction with what may be outmoded technologies. A good example is e-mail (70\% of which has been estimated to be spam) and which has been something of a headache for IT departments, managers and users alike. It has been suggested by J. P. Rangaswami (The e-mail killers, 2006), the architect of one of the few Enterprise 2.0 implementations to be written about, that "E-mail is now snailmail, no longer fit for purpose, although it served many glorious purposes for many years". At least within the enterprise, instant messaging and Wikis could make email obsolete. This possibility is strengthened by a survey undertaken in 2005 by Davenport (2005), who produced figures relating to the use made of e-mail by knowledge workers which showed that $26 \%$ thought it was overused in their organizations, $21 \%$ felt overwhelmed by it, and $15 \%$ felt that it actually diminished their productivity.

Any alternative that could reduce that degree of dissatisfaction is likely to be rapidly adopted. A further implication of this is that intranets could increasingly become communication channels rather than merely broadcasting mechanisms or databases created by silos.

\section{Enterprise 2.0}

The organisation that comes up most often as having implemented Enterprise 2.0 is the European investment bank Dresdner Kleinwort Wasserstein (the Wasserstein has recently been dropped). It has been claimed by its chief architect 
J. P. Rangaswami (2005; Burton, 2006) that the bank "started with Wikis in 1995 and blogs in 2002. The two initiatives were merged to make them easier to manage in 2004". Moreover, he adds that policies covering their appropriate use by staff were developed only in 2005 when "Most of the interested people got together and the guy most interested in it wrote the policy". Other accounts of experience are somewhat slow to appear though a few are available (Millen et al., 2005; Dodds, 2006; Wood, 2006). There may, of course, be other accounts scattered in the various magazine titles. The first of these papers reports on a research prototype of social bookmarking at IBM. Three additional techniques are being investigated: the first being "extension" whereby the evidence gleaned from individual tagging is used to infer the possible interest of the tagger in associated material (as pioneered on a large scale by Amazon), the second is to integrate an individual's bookmarks with other information sources provided by that individual, and the third would be to place bookmark collections from a group of individuals into Web sites maintained for various teams or projects. We can see evidence here of intelligent attempts to tailor social bookmarking towards the needs of the organization.

While it is probably too soon to devise generic guidelines for the implementation of Enterprise 2.0, some principles are beginning to emerge. One example has been put forward by Andrew McAfee (2006), writing in the MIT Sloan Management Review. He notes that "The technologists of Enterprise 2.0 are trying not to impose preconceived notions about how work should be categorized or structured. Instead, they're building tools that let these aspects emerge", and goes on to suggest six components with the acronym SLATES, as follows:

1. Search: McAfee notes that a Forrester survey found that less than half of the respondents found it easy to find what they were looking for on their intranets; while another survey found that $87 \%$ of Internet searchers reported having successful search experiences most of the time. From these figures McAfee infers that intranets are lagging behind the Internet in their effectiveness in searching, but these comparisons are almost certainly invalid because of different user groups and almost certainly different search needs. There is a big difference between looking for mission-critical information on an intranet and train times on the Internet. It is clear from the next section that McAfee is impressed by Google, and whereas it is not yet clear whether Google's special approach is valid in an organizational setting, the point made by McAfee that "users must be able to find what they are looking for" is self-evident.

2. Links: This is where McAfee pays tribute to the advances made by Google in this area. Others have already argued that it is hyperlinking that has made the Internet so attractive. 
3. Authoring: This is, perhaps one of the main Web 2.0 elements, the core aspect of harnessing collective intelligence through blogs and Wikis.

4. Tags: The second core Web 2.0 element is the folksonomy, and here McAfee envisages the usefulness of employees being able to tag intranet and Internet pages they have visited, see which other employees are using the same tags and what sites they have visited.

5. Extension: Here, in addition to the Amazon example mentioned above, McAfee draws attention to a browser toolbar called StumbleUpon. This device allows users to select a topic and then click on the "stumble" button. They're taken to a website on that topic, and if they like it they click on a "thumbs-up" icon, and if not on a "thumbs-down" alternative. They then "stumble" on to another site. Over time, StumbleUpon matches preferences in order to send users only to sites they like.

6. Signals: This is basically the RSS feed system mentioned earlier in the paper, designed to attack the problem of information overload, and it also has to be said, the relative unreliability of search engines, particularly in a corporate setting.

McAfee's SLATES framework reads like a re-listing of Web 2.0 elements supported by an unsubstantiated belief in the effectiveness of the technology. Tebbutt (2006) has written a more cautious article listing the possible barriers to attempting the implementation of an Enterprise 2.0 approach. Tebbutt, in conducting his survey, recognized that companies would be unlikely to go on record with their reasons for rejecting social computing so he talked instead to analysts, consultants and social computing adopters. The results were interesting, and perhaps not surprising. His analysis was presented under five headings:

\section{Losing control}

This is absolutely fundamental, and turned out to be the dominant concern. Some companies are nervous about giving their employees a voice, and believe that social computing could subvert the hierarchy and that staff would discover things that management would prefer to keep hidden. There is a fear that inviting comment on company policy and procedures could open the floodgates to an unmanageable torrent of poorly informed comment. (In fact, the UK government Department of Environment, Food and Rural Affairs has recently closed down a Wiki set up to gather public opinion on the grounds that it was being abused).

Despite his apparent enthusiasm for Enterprise 2.0, McAfee (2006) quotes the Management scholar Chris Argyris in acknowledging the human dimension. Argyris notes a distinction between people's espoused theories and their theoriesin-use. An espoused theory, for example might be, "I'm sincerely interested in learning, improvement and empowerment. I want to give the people in my 
organization all the tools they need to interact". Argyris found, though, that most people's theory-in-use is driven by (among other things) the need to remain in unilateral control and the desire to suppress negative feelings. When the two theories come into conflict, the theory-in-use usually wins.

\section{Never trust an employee}

This is related to the previous concern, and arises from the fact that many companies do not have enough faith in their employees to think that they will use such open systems effectively, or worse will waste time or leak confidential information to the outside world. The author of this paper knows of one multinational where anyone wishing to post material on the company intranet must seek permission from the lawyer attached to his or her department, a process which has been known to take three or four weeks. Tebbutt quotes the Research Director of Forrester as saying that "this lack of trust is due to the fact that senior management is largely made up of alpha males. Being in control is what they're good at and what they like, which is what brought them to the board seat to begin with".

\section{Heard it all before}

A number of other authors have also commented on this, for example Gotta (2004). One IT Director, quoted by Tebbutt, claimed that "You can't discount the fact that other tools, such as distribution lists, shared folders and eRooms come close in functionality". However, it should also be noted that some of the big vendors of portals and content management systems are beginning to incorporate blog and wiki facilities into their portfolios.

\section{Rejecting social computing}

A standard problem in change management is getting staff to drop old habits and ideas and to adopt new ways of working. The standard question raised when being told of some technological innovation is "What's in it for me?" In addition, the openness of social computing may, to some, be unnerving and the fear of exposure too great.

\section{Hierarchy anarchy}

Closely related to losing control and the lack of trust in employees comes the fear, particularly in middle management, that staff will bypass the hierarchy and the official channels if it makes life easier - or even more exciting. As social computing becomes entrenched a complementary power network emerges within the organisation. This concern is well summed up by a Chief Information Officer (McCue, 2006) in a debate on corporate blogs: "Blogs are popular because they tend to represent personal opinions and personality rather than corporate messages. Therefore we need to take a great deal of care to ensure appropriate use so we

Scire. 14 : 2 (jul.-dic. 2008) 13-29. ISSN 1135-3716. 
don't devalue the blog concept, whilst avoiding mayhem in what essentially needs to be a controlled message".

It is possible that these fears explain low take-up of Web 2.0 tools in a survey conducted by the ARK Group (2005) which asked respondents which technologies were considered to be the most important in collaborative working. With fifteen alternatives listed (some of which can be used in parallel) the results were:

$\begin{array}{ll}\text { E-mail } & 68 \% \\ \text { Document management } & 65 \% \\ \text { Intranet/portal } & 62 \% \\ \text { Communities of practice } & 61 \% \\ \text { Blogs } & 12 \% \\ \text { Wikis } & 12 \%\end{array}$

\section{Paradoxes and conclusions}

\subsection{General management and knowledge management}

The previous section was much concerned with management issues, and this seems to be the most important factor in considering the possible efficacy of implementing techniques of social computing within the enterprise. It is clear that some types of enterprise will be more amenable than others. Charles Handy, in a short, amusing but perceptive book entitled Gods of management (Handy, 1979) suggested that there were four broad types of organisation, typified by four Greek gods:

- Zeus, the Club culture (represented, in the book, by a spider's web). Zeus represented the patriarchal tradition, and is reflected in the small entrepreneurial firm, as well as in broking firms, investment banks and in many political groupings.

- Apollo, the Role culture (its picture is a Greek temple, where the pillars represent the functions and divisions in a role organisation, linked by tension wires of rules and procedures). Stability and predictability are encouraged. Handy cites life insurance companies as an almost perfect example of the Role culture.

- Athena, the Task culture (represented by a net). This culture is very different, one in which management is seen as being basically concerned with continuous and successful solution of problems. The organisation is a network of commando units, each unit being largely self-contained but with a specific responsibility within an overall strategy. This is similar to the matrix type of organisation used by NASA where teams are created from a common pool of expertise to tackle projects.

- Dionysus, the Existential culture (represented by a cluster of individual stars, loosely gathered in a circle). It is the culture preferred of professionals, and in the context of this paper is redolent of the Internet itself, where "professionals" are brought together by blogs and Wikis. Looking more closely at the different types of organisation suggested by Handy, it would seem on the face of it that the Zeus and Apollo cultures would not be such fertile grounds in which to plant social computing as might be the Athena and Dionysus cultures. However, Handy does

Scire. 14 : 2 (jul.-dic. 2008) 13-29. ISSN 1135-3716. 
point out that few organisations are purely one of the types suggested, most being a mixture, or rather an amalgamation, of different cultures.

It may follow then, that there are specific groups within organisations that could derive more benefit than others from social computing, and this is hardly surprising. Relevant here is a paper by Seely Brown and Duguid (2001) in which they say that "New knowledge, vital for growth, frequently emerges from small communities of practice. In other words, research groups often develop a common set of habits, customs, priorities and approaches that both produce new insights and enable them to flow with little attention to how they might be transferred to outsiders". This immediately suggests, and again it is not surprising, that it is communities of practice or communities of interest embedded within organisations who are most likely to be able to use, and profit from, social computing. And, echoing Handy, the authors go on to say: "When an organisation reaches a certain stage in its development, instead of developing like a self-organizing string quartet, it becomes more like an orchestra whose disparate sections now need a conductor. At that point, establishing business processes becomes important. Process helps coordinate different communities so that their practices, while allowed to flourish, don't grow out of touch with one another. Ideally, processes must permit rigor without rigidity. The balance is not easy to achieve. Process emphasizes the hierarchical explicit command-and-control side of organization - the structure that gets things done. By contrast, practice emphasizes the implicit coordination and exploration that produces things to do. Practice without process tends to become unmanageable; process without practice results in the loss of creativity needed for sustained innovation".

\subsection{Informed leadership and the "wisdom of the masses"}

One of the arguments put forward by enthusiasts for tagging on Internet sites is that the more people who contribute, the more one is likely to arrive at "the truth". Grant Campbell and Fast (2006) are most explicit about this: $a$ ) if you get enough people doing what they like - linking, tagging, sharing or subscribing interesting and useful patterns emerge; $b$ ) these patterns get more useful and more interesting as more people join in to do what they like; $c$ ) systems that exploit these patterns can scale to larger sizes in ways that traditional information systems, such as library catalogues, can not; $d$ ) systems with fewer rules and constraints are more likely to obtain widespread adoption and more likely to generate beneficial patterns.

In the context of this paper the words what they like and fewer rules and constraints stand out. The point about enough people is also important, and a story quoted originally in the journal Nature is often alluded to by proponents of tagging. Francis Galton (1907), the British polymath, reported on a small and informal 
experiment that he conducted at the beginning of the $20^{\text {th }}$ century. Galton collected 787 participants at a country fair to guess the weight of an ox. The participants were a mixture of farmers, butchers and ordinary bystanders. Galton took the answers and calculated both the median and mean estimates. The median guess was within $0.8 \%$ of the correct weight and the mean within $0.01 \%$. It is important to note a number of factors in this interesting experiment. First, the large number of people involved, probably far larger than might subscribe to a corporate blog or Wiki on a particular issue. Second, Galton was concerned with the discovery of a verifiable fact, not an opinion about some abstract issue (and the CIO quoted above was aware that blogs attract personal opinions and personality). The difference between guessing answers to fact-based questions and opinions about abstract issues is, of course, enormous, and one which becomes most apparent in public referenda on complex issues. The problem is one of organizational context. Referring to the quotation in the previous paragraph it is clear that opinions will be welcome in the area of "practice", especially from members of the community. It is less clear that opinions will be welcomed from senior management in the area of "process". An opinion, as expressed by a relatively junior employee, is couched within an individual context, comprising the set of facts and prior opinions available to that individual. That set is likely to be very different from that of a member of the Board. The consensus opinion of a majority of employees may send a powerful signal to senior management about the mood of the workforce, but may not always have much objective value in business terms.

Furthermore, individual stereotypes may come into play and skew the balance, particularly if the numbers contributing to a blog or wiki are small. Handy (1979) borrows, in his book, a typology of organisational characters which he points out are quite similar to his organisational stereotypes: the Jungle Fighter (whose goal is power), the Company Man (committed to maintaining the organisation's integrity), the Gamesman (a team player, playing for the corporation) and the Craftsman (interested in the process of making something). As it does not follow that individual stereotypes work exclusively for their corresponding organisational stereotypes, there is a further possibility of conflict within the organisation, though in the dialectic sense this can be fruitful.

\subsection{Knowledge management and Information management}

It is a truism to say that management thinking can be subject to fashionable waves as new and exciting ideas emerge, but it would be a mistake to suppose that the new wave replaces the status quo. It is unlikely that Web 2.0 will replace Web 1.0; more likely that it will be assimilated into the wide range of Internet facilities, though obviously affecting many aspects of Web 1.0 as it is assimilated. There is probably an even stronger argument to suggest that Enterprise 2.0 will not replace 
"Enterprise 1.0". At a lower level, it can be seen that there are many enthusiastic writers who proclaim that formal systems, such as library classifications and website taxonomies are now superseded by tagging and folksonomies, if only on the grounds that taxonomies are expensive to build and maintain, (for example Porter, 2006). But, as Macgregor and McCullough (2006) point out: "It is curious to note that during the period in which collaborative tagging has emerged, a reaffirmation of controlled vocabularies has arisen in parallel. The requirement for improved information organisation and management within the corporate sector has facilitated the increased deployment and development of corporate taxonomies".

If social computing is a tool to support knowledge management, as seems clear, then it will need to continue to be supported by, and integrated with, the more formal methods of information management. The four modes of knowledge conversion suggested by Nonaka and Takeuchi (1995) will still hold, viz: Socialization - from tacit knowledge to tacit knowledge; Externalization - from tacit knowledge to explicit knowledge; Combination - from explicit knowledge to explicit knowledge; Internalization - from explicit knowledge to tacit knowledge. These conversions must be designed, balanced and integrated.

\subsection{Information overload and technology overload}

The final paradox arises from the fact that new technologies, partly intended to combat information overload may actually contribute to it. Furthermore, unless we are careful they may actually contribute "inferior" information. Baroness Greenfield (2006), addressing the British House of Lords, reported on a study that had given her cause for concern with regard to the education of children, but which has wider implications. The report showed that a survey of eight to 18 year-olds had found that they were now spending an average of 6 _ hours a day using electronic media. The report concluded that "Screen culture is a world of constant flux of endless sound bites, quick cuts and half-baked ideas. It is a flow of gossip tidbits, news headlines and floating first impressions. Notions don't stand alone but are massively linked to everything else; truth is not delivered by authors and authorities but is assembled by the audience". If this phenomenon replicates itself in the increasingly fast-moving, competitive and mobile world of business, then there is a danger that there will be little time for reflection and the making of balanced judgements. It will be important to get the balance right in the design and use of the technologies on offer.

The conclusions may be summarised as follows:

- There is little doubt that a new wave of technologies, loosely called Web 2.0, has arrived and is likely to remain and to evolve.

- It does not follow, however, that these technologies are all necessarily appropriate for implementation in all corporate enterprises.

Scire. $14: 2$ (jul.-dic. 2008) 13-29. ISSN 1135-3716. 
- It is certainly likely that some of these technologies could be beneficial in certain areas of the enterprise, notably communities.

- This is, in effect, an extension of Knowledge management principles which are relatively well understood.

- Any attempt to embrace these technologies too widely, or without careful planning, will be doomed to failure, and likely to be counterproductive.

- In any case, such technologies and their adoption, should be allowed to evolve naturally rather than be imposed on the workforce.

- Replication of facilities already in place that do the same, or similar jobs, should be avoided - users can be easily confused by technological offerings.

- The possibilities should not, however, be rejected out of hand - there are useful technologies on offer, particularly if they are tailored to specific needs and circumstances.

- Wherever they are implemented, they should be supported by, and integrated with, the formal information management systems.

\section{Postscript}

The Web 2.0 debate has intensified since this paper was written last September. Larry Sanger, co-founder of the Wikipedia, has broken away to found the "Citizendium" (n. d.) a "citizens' compendium of everything", which will be an experimental new wiki project that combines public participation with gentle expert guidance.

Tim Berners-Lee, popularly known as the creator of the World Wide Web, has claimed that blogging is one of the biggest perils facing the web in that "there is a great danger that (the web) becomes a place where untruths start to spread more than truths" (Johnson, 2006).

Though it was reported that Bill Gates had dismissed Web 2.0 as hype, it is claimed that he says, in a leaked memo from within Microsoft, that "The broad and rich foundation of the internet will unleash a "services wave"" which "will be very disruptive". He says that "this next generation of the internet is being shaped by its 'grassroots' adoption and popularization model" and that Microsoft will be able to "deliver experiences and solutions across the entire range of workstyle and digital lifestyle scenarios" (2005), a statement which seems to resonate with the thinking of Tim O'Reilly (2005).

But what of the take-up of Web 2.0 technologies by enterprises? There are still few detailed accounts of wholesale adoption to be found, though it is reported that General Motors are making serious plans to exploit a wide range of Web 2.0 facilities. Fred Killeen, GM's chief systems and technology officer is keen to use Web 2.0 for collaborative working, including internally managed Wikis to support meetings with relevant material and definitions for terminology used, as well as folksonomies, which Killeen sees as avoiding the expense of creating formal 
taxonomies (Cliff, 2006). Gartner analyst Charles Abrams (Savvas, 2006) is quoted as "warning that businesses will ignore Web 2.0 at their peril", and goes on to list seven core benefits for businesses.

\section{References}

ARK Group Ltd. (2005). Collaborative working: a guide to best practice. London: ARK Group Ltd., 2005.

BlogsCanada. Blog definition. http://http://www.blogscanada.ca/BlogDefinition.html (2007-01-10).

Bradley, Phil (2006). Web 2.0 - a new generation of services. // Update. 5:5 (May 2006).

Buckley Owen, Tim (2006). Q\&A with Christopher Barger, IBM's Blogger-in-Chief. // FreePint Newsletter. 207 (8th June 2006). http://www.freepint.com/issues/080606.htm (2007-01-10).

Burton, Graeme (2006). Blogs and Wikis 'ten years in the making'. // Inside Knowledge. (June 2006). http://www.ikmagazine.com/display.asp?articleid+518C6580-B2D446A2-82FB- C72 (2007-01-10).

Citizendium: the citizens' compendium. http://www.citizendium.org (2007-01-10).

Davenport, T. H. (2005). Thinking for a living Boston. Harvard Business School Press, 2005.

Dodds, Leigh (2006). Embracing the Wiki way: deploying a corporate wiki. // FreePint. 27 (July 2006). http://www.freepint.com/issues/270706.htm\#tips (2007-01-10).

FreePint Newsletter 210 (27th July 2006). http://www.freepint.com/issues/270706.htm (2007-01-10).

FreePint Newsletter 213 (7th September 2006). http://www.freepint.com/issues/070906.htm (2007-01-10).

Galton, Francis (1907). Vox Populi. // Nature (1907) 450- 451.

Golder, Scott A.; A. Huberman, Bernardo (2005). The structure of collaborative tagging systems http://www.hpl.hp.com/research/idl/papers/tags/tags.pdf (2007-01-10).

Gotta, Mike (2004). Social computing - getting ahead of the blog. // ZDNet News: Apr 20, 2004 12:00:00 AM. http://news.zdnet.com/2100-6005_22-299431.html (2007-01-10).

Grant Campbell, D.; Fast, Karl V. (2006). From pace layering to resilience theory: the complex implications of tagging for information architecture. // Paper presented at the IA Summit 2006, Vancouver, 2327 March. http://www.iasummit.org/2006/files/ 164_Presentation_Desc.pdf (2007-01-10).

Greenfield, Susan (2006). Education: Science and Technology. // House of Lords debates. (20th April 2006). http://www.publications.parliament.uk/pa/ld200506/ldhansrd/ vo060420/text/60420-19.htm\#60420-19_spnew0 (2007-01-10).

Handy, Charles (1979). Gods of management. London: Pan Books, 1979

Hogge, Becky (2006). Calling time on the Wiki. // New Statesman. (4 September 2006). http://www.silicon.com/ciojury/0,3800003164,39162208,00.htm (2007-01-10).

IAI members discussion list, $n$. d.

Scire. 14 : 2 (jul.-dic. 2008) 13-29. ISSN 1135-3716. 
Johnson, Bobbie (2006). Creator of web warns of fraudsters and cheats. // The Guardian. (3 November 2006). http://www.guardian.co.uk/uk_news/story/0,,1938374,00.html (2007-01-10).

Kyrin, Jennifer. AJAX. // About.com. http://webdesign.about.com/od/ajax/g/bldefajax.htm (2007-01-10).

Longbottom, Clive (2006). Search engines need to start finding. // Computer Weekly. (20 June 2006).

Macgregor, George; McCulloch, Emma (2006). Collaborative tagging as a knowledge organisation and resource discovery tool. // Library Review. 55:5 (2006) 291-300.

MacManus, Richard (2005). Leaked Documents from Bill Gates and Ray Ozzie. // Richard MacManus. (November 9th, 2005). http://blogs.zdnet.com/web2explorer/index.php?p=52 (2007-01-10).

McAfee, Andrew P. (2006). Enterprise 2.0: the dawn of emergent collaboration. // MIT Sloan Management Review. 47:3 (Spring 2006) 21-28.

McCue, Andy (2006). CIO Jury: Corporate blogs more than a fad, but approach them with caution, say IT chiefs. // Silicon.com (8 September 2006).

Millen, David; Feinberg, Jonathan; Kerr, Bernard (2005). Social bookmarking in the enterprise. // Social computing. 3:9 (November 2005). http://acmqueue.com/ modules.php?name $=$ Content\&pa $=$ printer_friendly \&pid=344\&p $(2007-01-10)$.

Moody, Glyn (2006). This time, it'll be a Wikipedia written by experts. // The Guardian. IT Supplement. (13 July 2006).

Nonaka, Ikujiro; Takeuchi, Hirotaka (1995). The knowledge-creating company. London: Oxford UP, 1995.

O'Reilly, Tim (2005). What is Web 2.0. Design patterns and business models for the next generation of software. http://www.oreillynet.com/pub/a/oreilly/tim/news/2005/09/30/ what-is-web-20.html (2007-01-10).

Orlowski, Andrew (2006). A thirst for knowledge. // The Guardian. IT Supplement. (13 April 2006).

Porter, Joshua (2006). Folksonomies: a user driven approach to organizing content. // User Interface Engineering. 11 (2006). http://www.uie.com/events/uiconf/2006/articles/ folksonomies (2007-01-10).

Saran, Cliff (2006) Drive business change with Web 2.0. // Computer Weekly. (7 November 2006) $30,32$.

Savvas, Antony (2006). Ignore Web 2.0 at your peril, businesses warned. // Computer Weekly. (6 Dec 2006). http://http://www.computerweekly.com/Articles/2006/12/06/ 220396/ignore-web-2.0-at-your-peril-businesses-warned.htm (2007-01-10).

Schofield, Jack (2005). One foot in the future. // The Guardian (IT Supplement) (17 November 2005).

Schofield, Jack (2006). Harness the power of human users. // Computing Weekly. (5 September 2006) 28.

Seely Brown, John; Duguid, Paul (2001). Creativity versus structure: a useful tension. // MIT Sloan Management Review. (Summer 2001).

Social networking (2006). http://www.bitpipe.com/tlist/Social-Networking.html (2007-01-10).

Scire. 14 : 2 (jul.-dic. 2008) 13-29. ISSN 1135-3716. 
Tebbutt, David (2006). Genie in a bottle. // Information World Review. (May 2006) 19-21. The e-mail killers (quoting J. P. Rangaswami). // Information Age. (August 2006) 27.

Wikipedia contributors (2006a). Wiki. // Wikipedia, The Free Encyclopedia. October 26, 2006. http://en.wikipedia.org/wiki/Wiki (2007-01-10).

Wikipedia contributors (2006b). Competition. // Wikipedia, The Free Encyclopedia. October 26, 2006. http://www.en.wikipedia.org/wiki/Encyclop\%C3\%/A6dia_Britannica (200701-10).

Wikipedia contributors (2006c). Folksonomy. // Wikipedia, The Free Encyclopedia. October 26, 2006. http://en.wikipedia.org/wiki/Folksonomy (2007-01-10).

Wikipedia contributors (2006d). RSS. // Wikipedia, The Free Encyclopedia. October 26, 2006. http://www.en.wikipedia.org/wiki/RSS_(file_format) (2007-01-10).

Wikipedia contributors (2006e). Aggregator. // Wikipedia, The Free Encyclopedia. October 26, 2006. http://www.en.wikipedia.org/wiki/Aggregator (2007-01-10).

Wikipedia contributors (2006f). Mashup. // Wikipedia, The Free Encyclopedia. October 26, 2006. http://www.en.wikipedia.org/wiki/Mashup (2007-01-10).

Wikipedia contributors (2006g). Podcasting. // Wikipedia, The Free Encyclopedia. October 26, 2006. http://www.en.wikipedia.org/wiki/Podcasting (2007-01-10).

Wikipedia contributors (2006h). Social bookmarking. // Wikipedia, The Free Encyclopedia. October 26, 2006. http://en.wikipedia.org/wiki/Social_bookmarking (2007-01-10).

Wood, Emma. Emulating Web tools to become indispensable to your users. // Fumsi. (Sept. 2006). http://web.fumsi.com/go/article/share/2540 (2007-01-10). 